\title{
When Is the Hippocampus Involved in Recognition Memory?
}

\author{
Gareth R. I. Barker and Elizabeth C. Warburton \\ Medical Research Council Centre for Synaptic Plasticity, School of Physiology and Pharmacology, University of Bristol, Bristol BS8 1TD, United Kingdom
}

The role of the hippocampus in recognition memory is controversial. Recognition memory judgments may be made using different types of information, including object familiarity, an object's spatial location, or when an object was encountered. Experiment 1 examined the role of the hippocampus in recognition memory tasks that required the animals to use these different types of mnemonic information. Rats with bilateral cytotoxic lesions in the hippocampus or perirhinal or prefrontal cortex were tested on a battery of spontaneous object recognition tasks requiring the animals to make recognition memory judgments using familiarity (novel object preference); object-place information (object-in-place memory), or recency information (temporal order memory). Experiment 2 examined whether, when using different types of recognition memory information, the hippocampus interacts with either the perirhinal or prefrontal cortex. Thus, groups of rats were prepared with a unilateral cytotoxic lesion in the hippocampus combined with a lesion in either the contralateral perirhinal or prefrontal cortex. Rats were then tested in a series of object recognition memory tasks. Experiment 1 revealed that the hippocampus was crucial for object location, object-in-place, and recency recognition memory, but not for the novel object preference task. Experiment 2 revealed that object-in-place and recency recognition memory performance depended on a functional interaction between the hippocampus and either the perirhinal or medial prefrontal cortices. Thus, the hippocampus plays a role in recognition memory when such memory involves remembering that a particular stimulus occurred in a particular place or when the memory contains a temporal or object recency component.

\section{Introduction}

Recognition memory involves making judgments about whether a stimulus has been encountered before. However, it can be argued that recognition memory is not a unitary process, as distinct types of information are used to form judgments of prior occurrence, including the relative familiarity of an object or location or when or where an object was previously encountered (recency/temporal order memory or object-in-place memory, respectively).

Investigations of the neural basis of recognition memory have implicated several brain regions. Lesions in the perirhinal cortex severely disrupt object recognition (Mumby and Pinel, 1994; Ennaceur et al., 1996; Bussey et al., 1999; Norman and Eacott, 2004) and object-in-place memory and temporal order recognition memory (Hannesson et al., 2004; Barker et al., 2007), but not object location memory (Ennaceur et al., 1996; Glenn and Mumby, 1998; Barker et al., 2007). Lesions of the medial prefrontal cortex disrupt temporal order and object-in-place memory yet have no effect on object recognition (Barker et al., 2007). Further disconnection of the perirhinal and medial prefrontal cortices significantly impairs both object-in-place and temporal order memory (Barker et al., 2007), showing that, depending on the

\footnotetext{
Received Dec. 9, 2010; revised May 23, 2011; accepted June 3, 2011.

Author contributions: E.C.W. designed research; G.R.I.B. and E.C.W. performed research; G.R.I.B. analyzed data; E.C.W. wrote the paper.

This work was supported by a project grant from the Biotechnology and Biological Sciences Research Council. We thank Jane Robbins and Katherine Narduzzo for assistance with histology.

Correspondence should be addressed to Dr. Elizabeth C. Warburton, School of Physiology and Pharmacology, University of Bristol, Medical Sciences Building, University Walk, Bristol BS8 1TD, United Kingdom. E-mail: e.c.warburton@bristol.ac.uk.

DOI:10.1523/JNEUROSCI.6413-10.2011

Copyright $\odot 2011$ the authors $\quad 0270-6474 / 11 / 3110721-11 \$ 15.00 / 0$
}

nature of the recognition memory judgment, these cortical regions may function within a neural circuit.

The role of the hippocampus in recognition memory is controversial. While a number of studies show that hippocampal or fornix lesions produce no effect in object recognition (Bussey et al., 2000; Mumby et al., 2002; Winters et al., 2004; Forwood et al., 2005; Good et al., 2007; Langston and Wood, 2010), other studies report significant impairments (Clark et al., 2000, 2001). In contrast, object-in-place memory is impaired following fornix lesions (Bussey et al., 2000) and hippocampal lesions impair temporal order discriminations (Kesner and Novak, 1982; Chiba et al., 1994; Vorobyov, 1998; Fortin et al., 2002). Thus, under conditions in which recognition memory has a spatial or temporal component, the hippocampus appears to be critical.

The hippocampus is anatomically connected with the perirhinal and prefrontal cortices (Jay and Witter, 1991; Burwell et al., 1995) and thereby is in a position to functionally interact with both regions. The present study tested two hypotheses: first, the hippocampus plays a selective role in recognition memory tasks requiring the subject to use spatial or recency/temporal order information; and second, that the hippocampus functionally interacts with either the perirhinal or medial prefrontal cortex during these recognition memory tasks. To test the first hypothesis, animals with bilateral lesions in the hippocampus, medial prefrontal cortex, and perirhinal cortex were compared in a battery of recognition memory tasks. The second hypothesis was tested by disconnecting the hippocampus from either the perirhinal or medial prefrontal cortex in the same or opposite hemisphere. If the hippocampal-cortical regions are functionally interdependent, then animals with contralateral lesions should be more impaired than animals with ipsilateral lesions (Warburton et al., 
2000, 2001; Barker et al., 2007). If, however, the regions operate independently, then contralateral lesions should have no effect, even when bilateral lesions of the two regions significantly impair performance (Block et al., 2007).

\section{Materials and Methods}

All experiments were conducted in male pigmented rats (DA strain, weighing 230-250 g at the start of the experiments; Bantin and Kingman). The animals were housed in pairs under a 12/12 h light/dark cycle (light phase, 18:00-6:00 h). Behavioral training and testing were conducted during the dark phase of the cycle. Food and water were available ad libitum throughout the experiment. All animal procedures were performed in accordance with United Kingdom Animals Scientific Procedures Act (1986) and associated guidelines. All efforts were made to minimize any suffering and the number of animals used.

\section{Surgery}

Rats were divided into two cohorts that were tested independently. Rats in the first group were subdivided into four groups: bilateral perirhinal cortex (PRH) lesions, bilateral medial prefrontal cortex (mPFC) lesions, bilateral hippocampal (HPC) lesions, and surgical controls (SHAM). Rats in the disconnection groups were divided into four groups and received one of the following combinations of lesions: (1) unilateral PRH lesions combined with a unilateral HPC lesion in the opposite hemisphere (PRH + HPC Contra), (2) unilateral PRH lesions and unilateral HPC lesion in the same hemisphere (PRH + HPC Ipsi), (3) a unilateral mPFC lesion combined with a HPC lesion in the opposite hemisphere (mPFC + HPC Contra), and (4) a unilateral mPFC lesion combined with a HPC lesion in the same hemisphere (mPFC + HPC Ipsi). The Ipsilesioned groups served as controls for the Contra-lesioned groups.

Each rat was anesthetized with isoflurane (induction, 4\%; maintenance, $2-3 \%$ ) and secured in a stereotaxic frame with the incisor bar set at the appropriate level (for the PRH or mPFC lesion surgery, the bar was set at $+5 \mathrm{~mm}$ above the interaural line; for the HPC lesion surgery, the incisor bar was set so as to achieve flat skull). The scalp was then cut and retracted to expose the skull. Craniotomies were then made directly above the target regions, and the dura cut to expose the cortex.

The PRH or mPFC lesions were made by injecting $0.09 \mathrm{M}$ NMDA (Sigma) dissolved in phosphate buffer, $\mathrm{pH}$ 7.2. The HPC lesions were made by injecting $0.06 \mathrm{M}$ NMDA. All the injections were made through a $1 \mu \mathrm{l}$ Hamilton syringe into the appropriate sites in the hemisphere.

For the PRH and HPC lesions, each injection was made gradually over a $3 \mathrm{~min}$ period and the needle was left in situ for a further $3 \mathrm{~min}$ before being withdrawn; for the mPFC lesions, each injection was made over a 4 min period and the needle left in situ for a further $4 \mathrm{~min}$ (due to greater volume of fluid). For the PRH lesions, the anterior-posterior (AP), lateral (LAT), and dorsoventral (DV) stereotaxic coordinates were calculated relative to bregma. For the $\mathrm{MPFC}$ and HPC lesions, the AP and LAT coordinates were calculated relative to bregma and the DV coordinates were calculated relative to the top of the cortex. The coordinates used and the amount of neurotoxin injected are shown in Tables 1, 2, and 3. The left $(\mathrm{LAT}+)$ and right $(\mathrm{LAT}-)$ hemispheres were targeted in different animals.

Sham control lesions of these structures were made using the procedure described above, but in these cases, the injection needle was lowered to the level of the target structure and left in place for the appropriate length of time before being removed.

At the completion of surgery, the skin was sutured and an antibiotic powder (Acramide; Dales Pharmaceuticals) was applied. All animals then received a single administration of $5 \mathrm{ml}$ of glucose saline subcutaneously and systemic analgesia intramuscularly $(0.05 \mathrm{ml}$ Temgesic; Reckett and Colman). All animals were allowed to recover for at least $10 \mathrm{~d}$ before habituation to the testing arena began.

\section{Histology}

At the end of the experiment, each rat was anesthetized with Euthetal (Rhône Mérieux) and perfused transcardially with PBS followed by $4 \%$ paraformaldehyde. The brain was postfixed in paraformaldehyde for a minimum of $2 \mathrm{~h}$ before being transferred to $30 \%$ sucrose in $0.2 \mathrm{M}$ phos-
Table 1. Lesion coordinates for the hippocampus relative to bregma

\begin{tabular}{rllll}
\hline & AP & LAT $( \pm)$ & DV & Volume of 0.06 м NMDA \\
\hline 1 & -2.1 & 1.1 & -3.5 & $0.1 \mu \mathrm{l}$ \\
2 & -2.5 & 1.0 & -3.7 & $0.1 \mu \mathrm{l}$ \\
3 & -2.5 & 2.2 & -3.6 & $0.1 \mu \mathrm{l}$ \\
4 & -3.0 & 1.2 & -3.4 & $0.1 \mu \mathrm{l}$ \\
5 & -3.0 & 2.5 & -3.5 & $0.1 \mu \mathrm{l}$ \\
6 & -4.0 & 2.5 & -3.0 & $0.1 \mu \mathrm{l}$ \\
7 & -4.0 & 4.1 & -4.0 & $0.15 \mu \mathrm{l}$ \\
8 & -4.0 & 5.5 & -5.1 & $0.15 \mu \mathrm{l}$ \\
9 & -4.5 & 2.5 & -3.4 & $0.15 \mu \mathrm{l}$ \\
10 & -4.5 & 4.5 & -4.0 & $0.15 \mu \mathrm{l}$ \\
11 & -5.2 & 4.5 & -4.2 & $0.15 \mu \mathrm{l}$ \\
12 & -5.6 & 4.6 & -6.6 & $0.15 \mu \mathrm{l}$ \\
13 & -6.0 & 4.2 & -3.8 & $0.15 \mu \mathrm{l}$ \\
\hline
\end{tabular}

In the unilateral lesioned animals, the left (LAT+) and right (LAT-) hemispheres were targeted in different animals.

Table 2. Lesion coordinates for the MPFC relative to bregma

\begin{tabular}{lllll}
\hline & AP & LAT $( \pm)$ & DV & Volume of 0.09 м NMDA \\
\hline 1 & +2.7 & 0.7 & -4.5 & $0.28 \mu \mathrm{l}$ \\
2 & +2.7 & 0.7 & -2.2 & $0.28 \mu \mathrm{l}$ \\
3 & +4.0 & 0.7 & -3.5 & $0.28 \mu \mathrm{l}$ \\
4 & +4.0 & 0.7 & -2.0 & $0.28 \mu \mathrm{l}$ \\
\hline
\end{tabular}

Table 3. Lesion coordinates for the PRH relative to bregma

\begin{tabular}{lllll}
\hline & AP & LAT & DV & Volume of 0.09 м NMDA \\
\hline 1 & -1.2 & \pm 5.8 & -9.3 & $0.18 \mu \mathrm{l}$ \\
2 & -3.2 & \pm 6.1 & -9.5 & $0.18 \mu \mathrm{l}$ \\
3 & -4.7 & \pm 6.2 & -9.1 & $0.18 \mu \mathrm{l}$ \\
\hline
\end{tabular}

phate buffer and left for $48 \mathrm{~h}$. Coronal sections were cut at $50 \mu \mathrm{m}$ on a cryostat and stained with cresyl violet.

To determine the extent of damage and the total area of tissue remaining in each of the structures that contained a lesion, the remaining area of the target structure was measured (Leica Qwin V3) in every fourth section between the following anterior-posterior coordinates relative to bregma: $\mathrm{mPFC}+4.70 \mathrm{~mm}$ to $+2.2 \mathrm{~mm}$, HPC $-1.9 \mathrm{~mm}$ to $-6.3 \mathrm{~mm}$, $\mathrm{PRH}-4 \mathrm{~mm}$ to $-7.8 \mathrm{~mm}$. The size of lesion was determined by comparing the total area remaining of each structure in each lesioned animal to the equivalent area in the sham-operated animals $(100-($ lesion area/sham area $\left.)^{\star} 100\right)$ ) and average lesion sizes for each group were determined. Additional sections were studied under the light microscope to identify incidental damage outside the targeted regions (see Results, below).

\section{Apparatus}

Exploration occurred in an open-top arena $(50 \times 90 \times 100 \mathrm{~cm})$ made of wood. The walls inside the arena were surrounded with a black cloth to a height of $1.5 \mathrm{~m}$ so that no external stimuli could be seen during the experiment (the black cloth was removed for the object-in-place and object location tasks), and the floor of the arena was covered with sawdust. An overhead camera and a video recorder were used to monitor and record the animal's behavior for subsequent analysis. The stimuli presented were objects constructed from Duplo blocks (Lego); varied in shape, color, and size $(9 \times 8 \times 7 \mathrm{~cm}$ to $25 \times 15 \times 10 \mathrm{~cm})$; and were too heavy for the animals to displace.

\section{Behavioral testing}

Pretraining. After being handled for a week, the animals were habituated to the arena without stimuli for 10-15 min daily for $4 \mathrm{~d}$ before the commencement of the behavioral testing.

Novel object preference task. This procedure was comprised of an acquisition phase and a recognition test, separated by a delay. In the acquisition phase, two identical objects (e.g., A1 and A2) were placed near the 
A Novel object preference
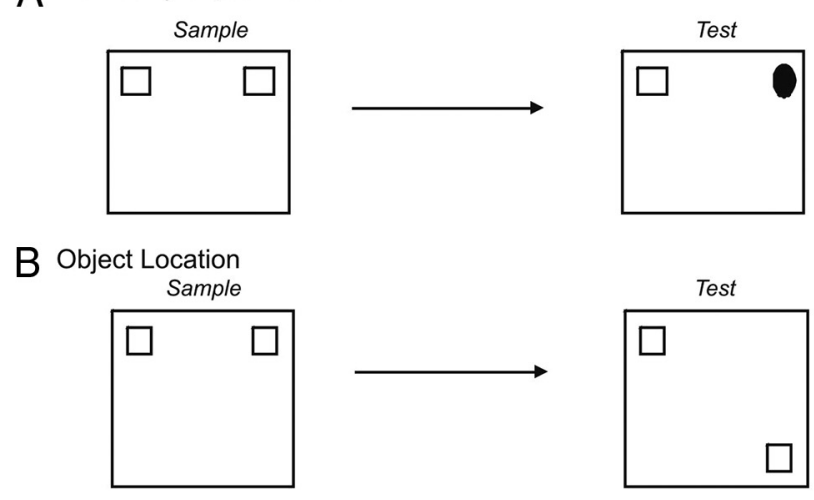

C Object-in-place
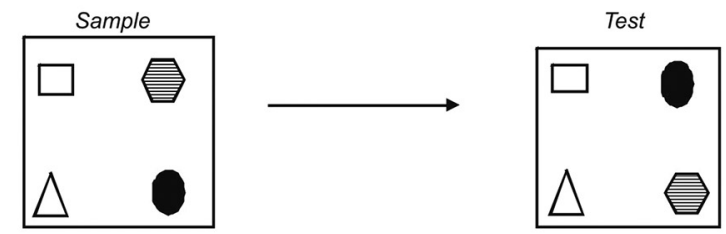

\section{Temporal order}

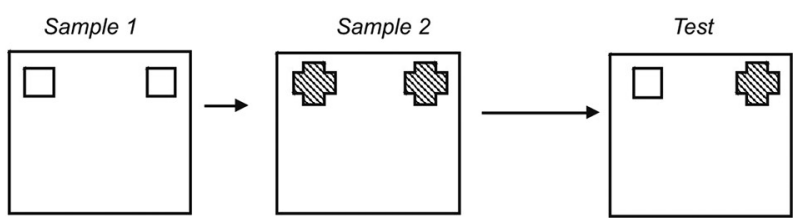

Figure 1. $A-D$, Diagrams of the four object recognition memory tasks: novel object preference task $(\boldsymbol{A})$, object location task (B), object-in-place task (C), and temporal order task (D).

corners on one wall in the arena $(10 \mathrm{~cm}$ from each adjacent wall) (Fig. $1 A$ ). The animal was placed into the arena facing the center of the opposite wall and allowed a total of either $40 \mathrm{~s}$ of exploration of A1 and A2 or $4 \mathrm{~min}$ in the arena. Exploratory behavior was defined as the animal directing its nose toward the object at a distance of $<2 \mathrm{~cm}$. Other behaviors such as looking around while sitting on or resting against the object were not considered as exploration. The delay between the sample and test phase was $5 \mathrm{~min}, 1 \mathrm{~h}$, or $24 \mathrm{~h}$. At test ( 3 min duration), the animal was placed in the arena and presented with two objects in the same positions as at acquisition: one object (A3) was the third copy of the object used in the acquisition phase and the other was a novel object (B3). The positions of the objects in the test and the objects used as novel or familiar were counterbalanced between the animals in a group and between the control and drug-treated groups.

Object location task. In this test, the rat's ability to recognize that an object it had experienced before had changed location was assessed. In the acquisition phase, the rat was exposed to objects A1 and A2, which were placed in the far corners of the arena (as in the object recognition test) (Fig. $1 B$ ). The animal was allowed to explore both objects during a sample phase of $3 \mathrm{~min}$, and the amount of exploration of each object was recorded by the experimenter. After a delay of $5 \mathrm{~min}$ or $24 \mathrm{~h}$, the test phase began in which object $\mathrm{A} 3$ was placed in the same position that object A1 had occupied in the sample phase. Object A4 was placed in the corner adjacent to the original position of A2, so that the two objects A3 and A4 were diagonal from each other. Thus, both objects in the test phase were equally familiar, but one was in a new location. The position of the moved object was counterbalanced between rats.

Object-in-place task. This task was comprised of an acquisition phase and a test phase separated by a 5 min delay (Fig. 1C). In the acquisition phase, the subjects were presented with four different objects (A-D). These objects were placed in the corners of the arena $15 \mathrm{~cm}$ from the walls. Each subject was placed in the center of the arena and allowed to explore the objects for $5 \mathrm{~min}$. During the delay period, all the objects were cleaned with alcohol to remove olfactory cues and any sawdust that had stuck to the object. In the test phase, two of the objects, e.g., B and D (which were both on the left or right of the arena), exchanged positions and the subject was allowed to explore the objects for $3 \mathrm{~min}$. The time spent exploring the two objects that had changed position was compared with the time spent exploring the two objects that had remained in the same position. The objects moved (i.e., those on the left or right) and the position of the objects in the sample phase were counterbalanced between rats. If object-in-place memory is intact, the subject should spend more time exploring the two objects that are in different locations compared with the two objects that are in the same locations.

Temporal order task. This task was comprised of two sample phases and one test trial (Fig. 1D). In each sample phase, the subjects were allowed to explore two copies of an identical object for a total of $4 \mathrm{~min}$. Different objects were used for sample phases 1 and 2, with a delay between the sample phases of $1 \mathrm{~h}$. The test trial ( 3 min duration) was given $3 \mathrm{~h}$ after sample phase 2. During the test trial, a third copy of the objects from sample phase 1 and a third copy of the objects from sample phase 2 were used. The positions of the objects in the test and the objects used in sample phases 1 and 2 were counterbalanced between the animals. If temporal order memory is intact, the subjects should spend more time exploring the object from sample 1, i.e., the object presented less recently, compared with the object from sample 2, i.e., the new object.

\section{Behavioral measures and statistical analyses}

All measures of exploration were made with the experimenter blind to the lesion status of each animal. Exploratory behavior was defined as the animal directing its nose toward the object at a distance of $<2 \mathrm{~cm}$. Any other behavior, such as looking around while sitting on or resting against the object, was not considered as exploration. Any subjects that failed to complete a minimum of $15 \mathrm{~s}$ exploration in the sample phase or $10 \mathrm{~s}$ of exploration in the test phase were excluded from the analysis. Discrimination between the objects was calculated using a discrimination ratio (DR), calculated as the absolute difference in the time spent exploring the novel and familiar objects divided by the total time spent exploring the objects, which takes into account individual differences in the total amount of exploration (Ennaceur and Delacour, 1988; Dix and Aggleton, 1999). Performance of the animals in the bilateral lesion groups (SHAM, HPC, PRH, mPFC) were compared statistically against each other, while the performance of animals with unilateral combined lesions in either the $\mathrm{PRH}+\mathrm{HPC}$ (Contra and Ipsi) or mPFC + HPC (Contra and Ipsi) were compared. Group comparisons used ANOVA followed by post hoc Newman-Keuls tests. Additional analyses examined whether individual groups had discriminated between the objects, using a within-subjects $t$ test (two-tailed). All statistical analyses used a significance level of 0.05 .

\section{Results}

\section{Histology}

Bilateral mPFC lesion group

All animals $(n=12)$ received significant bilateral lesions in the prelimbic and infralimbic areas of the medial prefrontal cortex. Two animals had some minor unilateral sparing in the posterior prelimbic cortex and 10 animals had minor sparing in the most posterior region of the infralimbic cortex. An average of $79 \%$ $( \pm 1.1 \%)$ of the medial prefrontal cortex was damaged across animals, ranging from $72-86 \%$ in total. The size of the lesion was not correlated with the extent of the behavioral deficit found $(p>$ 0.1 for all recognition memory tests). All animals had additional minor damage in the medial orbital cortex, anterior cingulate cortex, and motor cortex. Six animals also had minor damage to the lateral septum. The cases with the largest and smallest lesions are shown in Figure $2 A$.

\section{Bilateral PRH lesion group}

All animals $(n=10)$ received significant bilateral lesions in the perirhinal cortex. In six animals, this damage was complete; in 


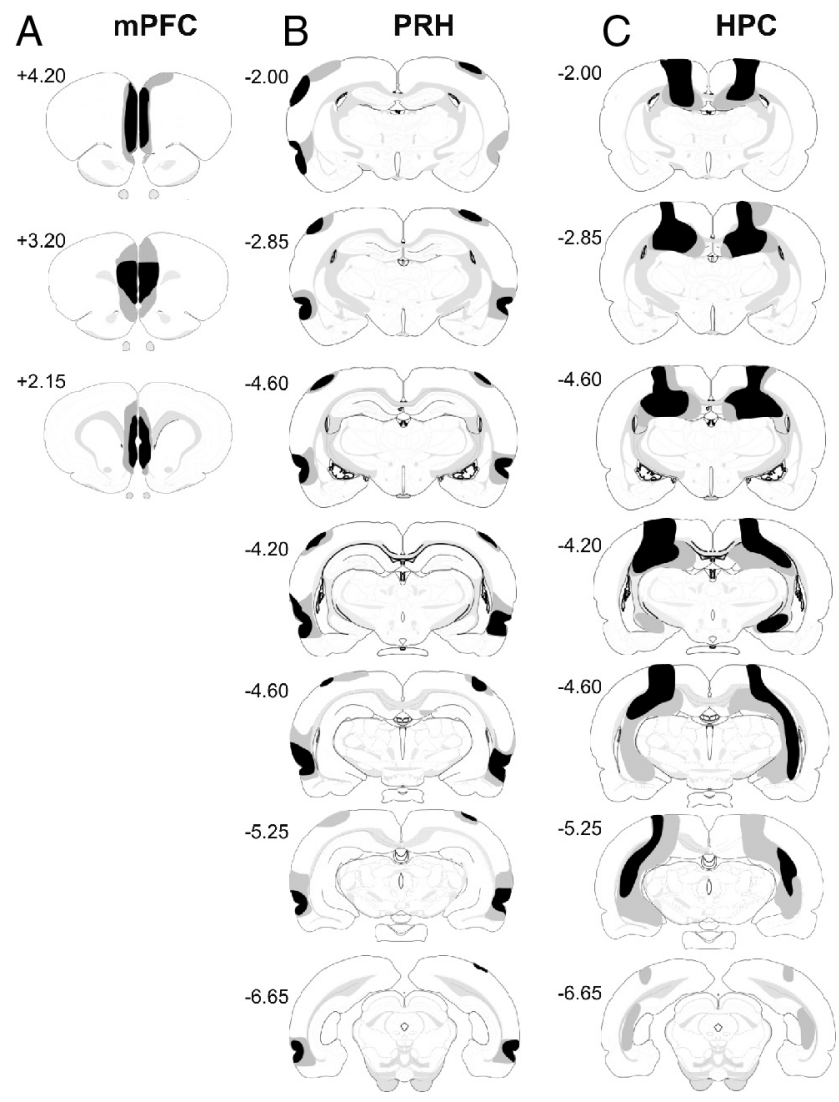

Figure 2. Diagrammatic reconstructions showing the cases with the largest (gray) and smallest (black) lesions in the $\operatorname{mPFC}(\boldsymbol{A}), \operatorname{PRH}(\boldsymbol{B})$, and $\mathrm{HPC}(\boldsymbol{C})$ groups. The numbers correspond to the approximate position relative to bregma (Swanson, 1998).

the remaining four animals, there was some unilateral sparing in the most anterior portion. An average of $84 \%( \pm 4.0 \%)$ of the perirhinal cortex was damaged across animals, ranging from $58-$ $98 \%$ in total. The size of the lesion was not correlated with the extent of the behavioral deficit found ( $p>0.1$ for all recognition memory tests). All animals had additional damage in area TE and minor damage in the dorsal region of the lateral entorhinal cortex. Three animals also had minor unilateral damage to the postrhinal cortex. All animals had minor damage to somatosensory and visual cortex. Nine animals had minor damage to piriform cortex and eight animals had minor damage to auditory cortex. The cases with the largest and smallest lesions are shown in Figure $2 B$.

\section{Bilateral HPC lesion group}

All animals $(n=10)$ had almost complete cell loss in the dorsal hippocampus (CA1, CA2, CA3) and dentate gyrus (DG). In three animals there was unilateral sparing of the medial DG and four animals had bilateral sparing of medial DG. Damage in the ventral hippocampus was less complete. In eight animals there was sparing at the ventral tip of the hippocampus; of these, five had bilateral sparing of the posterior CA3 and the medial blade of the DG. In two other animals, the ventral hippocampus was largely spared. Two animals had bilateral damage in the ventral subiculum. An average of $58 \%$ ( $\pm 5.8 \%)$ of the hippocampus was damaged across animals, ranging from $40-93 \%$ in total. The size of the lesion was not correlated with the extent of the behavioral deficit found ( $p>0.1$ for all recognition memory tests). In addition to the intended damage to the hippocampus, all animals had some damage to the overlying cortical regions, including primary somatosensory cortex, visual cortex, and posterior parietal cortex; in six animals the damage was minor. The cases with the largest and smallest lesions are shown in Figure 2C.

\section{PRH + HPC Contra}

All animals $(n=10)$ had significant unilateral damage to the perirhinal cortex. In nine animals there was near complete cell loss while one animal had some sparing in the most anterior portion of the perirhinal cortex. An average of $85 \%( \pm 3.6 \%)$ of the perirhinal cortex was damaged across animals, ranging from $63-99 \%$ in total. All animals had additional damage in anterior area Te2, although in four animals this damage was not substantial. Two animals had minor damage in ventral auditory cortex. In all animals there was damage in lateral entorhinal cortex and in one animal there was minor damage to piriform cortex. In addition, in two animals the lesion extended into the postrhinal cortex, producing minor damage.

All animals had major cell loss in the dorsal hippocampus. In four animals the cell loss was complete, while in five animals there was some sparing of the dentate gyrus and in one animal there was sparing of both the dentate gyrus and medial region of CA1. Four animals had major cell loss in the ventral hippocampus; the remaining six animals had only moderate cell loss. In some animals the lesion extended into the subiculum: in five animals there was damage to the dorsal subiculum and in seven animals there was damage to the ventral subiculum; the damage was minor in all animals. An average of $54 \%( \pm 4.3 \%)$ of the hippocampus was damaged across animals, ranging from $35-68 \%$ in total.

In all animals there was minor bilateral damage to primary somatosensory cortex and visual cortex. In addition, in one animal there was minor bilateral damage to the posterior parietal cortex; in all other animals damage to the posterior parietal cortex was unilateral. The cases with the largest and smallest lesions are shown in Figure $3 A$.

\section{PRH + HPC Ipsi}

All animals $(n=9)$ had significant damage to the perirhinal cortex. In seven animals the lesion was almost complete; two animals had sparing of the posterior perirhinal cortex. An average of $86 \%( \pm 2.4 \%)$ of the perirhinal cortex was damaged across animals, ranging from $74-94 \%$ in total. In all animals the lesion extended dorsally into area Te2, although posterior areas of Te2 were spared and in four animals there was minor damage in the ventral auditory cortex. In all animals there was additional minor damage in the lateral entorhinal cortex. In addition, two animals had minor damage in the postrhinal cortex.

All animals had major cell loss in the dorsal hippocampus. In seven animals, this cell loss was almost complete; four animals had only minor sparing in the dentate gyrus, while two other animals had some sparing of the medial region of the CA1 and the dentate gyrus. In six animals, damage to the ventral hippocampus was extensive, with sparing restricted to the ventral tip of the hippocampus and posterior portion of CA3. In three animals, the damage to the ventral hippocampus was minor. In four animals there was damage to the dorsal subiculum and in six animals there was damage to the ventral subiculum; in all animals this damage was minor. An average of $61 \%( \pm 2.3 \%)$ of the hippocampus was damaged across animals, ranging from $52-70 \%$ in total.

All animals suffered additional unilateral damage to cortical regions overlying the hippocampus and perirhinal cortex. In eight animals there was major unilateral damage to the posterior region of primary somatosensory cortex; however, the anterior 


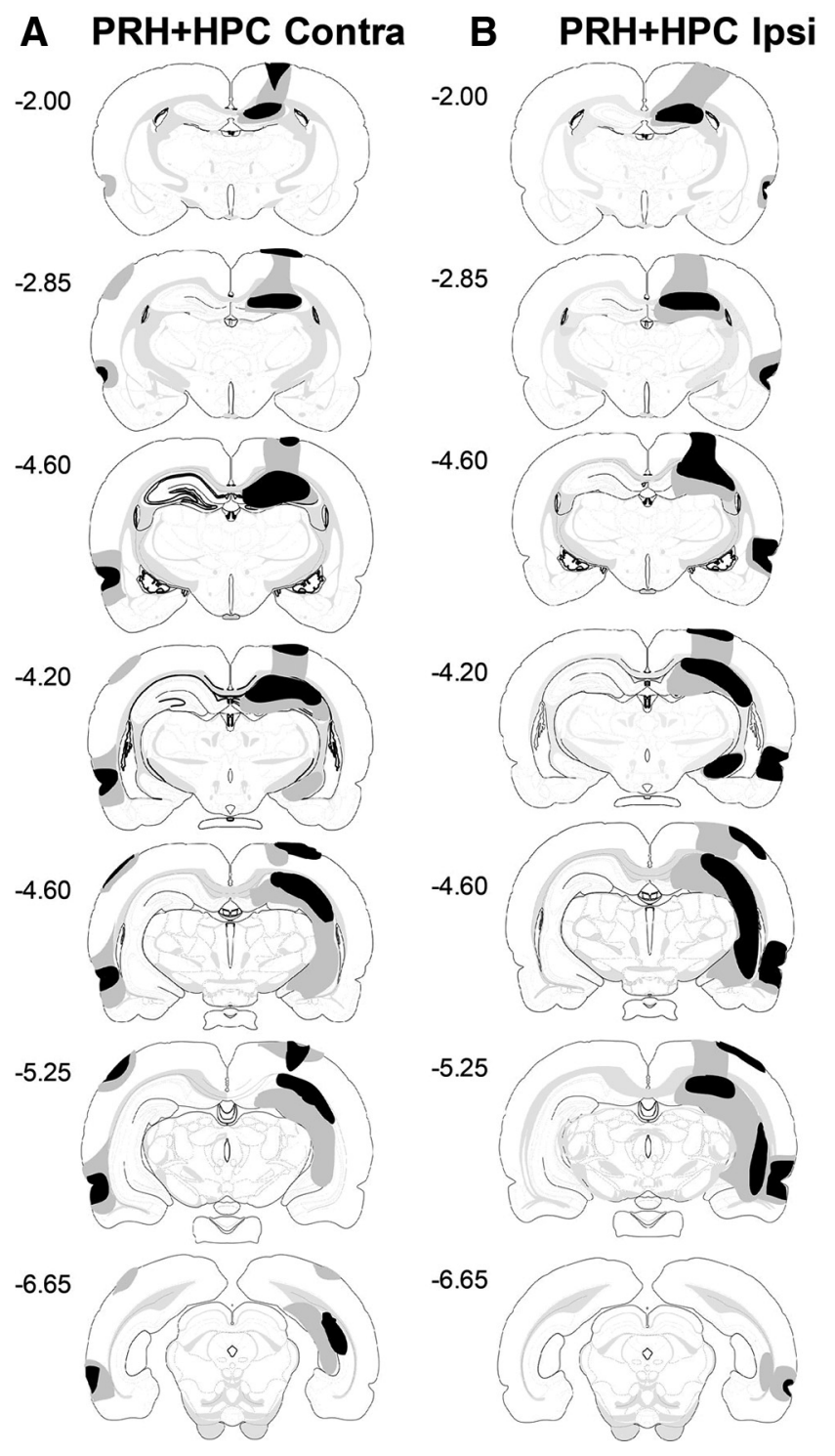

Figure 3. Diagrammatic reconstructions showing the cases with the largest (gray) and smallest (black) lesions in the PRH + HPC Contra group $(\boldsymbol{A})$ and PRH + HPC Ipsi group $(\boldsymbol{B})$. The numbers correspond to the approximate position from bregma (Swanson, 1998).

regions were spared. In one animal there was minor damage to primary somatosensory cortex. All animals had some unilateral damage to visual cortex, in eight animals this damage was minor; however, in one animal damage was major in the anterior region, although there was sparing of more posterior regions of visual cortex. All animals suffered some damage to the posterior parietal cortex: in four animals the damage was major and in five animals it was minor. The cases with the largest and smallest lesions are shown in Figure $3 B$.

mPFC + HPC Contra

All animals $(n=10)$ had significant unilateral damage to the prelimbic and infralimbic cortices. In seven animals, damage to the prelimbic cortex was complete, while three animals had sparing in the dorsal anterior-dorsal region. All animals had major damage to the infralimbic cortex with minor sparing in the most posterior portion. An average of $74 \%( \pm 4.5 \%)$ of the medial prefrontal cortex was damaged across animals, ranging from 51$85 \%$ in total. All animals had additional minor damage in the anterior cingulate cortex and in seven animals there was minor damage in the medial orbital cortex. Additionally, all animals had minor damage to the secondary motor area, seven animals had minor damage to the lateral septum, two animals had minor damage to the striatum, and one animal had minor damage to the nucleus accumbens.

In all animals there was extensive cell loss in the dorsal hippocampus. In four animals there was minor sparing in the dentate gyrus and in two other animals there was sparing of the medial region of the CA1 and the dentate gyrus. The lesion in the ventral hippocampus was less complete. Three animals sustained major damage to the ventral hippocampus with sparing occurring in the ventral tip and posterior portion of CA3 while seven animals had only minor damage to the ventral hippocampus. In three animals there was damage to the dorsal subiculum and in four animals there was minor damage to the ventral subiculum. An average of $57 \%( \pm 3.7 \%)$ of the hippocampus was damaged across animals, ranging from $49-71 \%$ in total. In addition, all animals suffered some damage to cortical regions overlying the hippocampus, including minor damage to the primary somatosensory cortex, visual cortex, and posterior parietal cortex. The cases with the largest and smallest lesions are shown in Figure $4 \mathrm{~A}$.

$m P F C+$ HPC Ipsi

All animals $(n=10)$ had significant unilateral damage to the prelimbic and infralimbic cortices. In six animals damage to the prelimbic cortex was complete, while in the remaining four animals there was sparing in the anterior-dorsal portion. An average of $69 \%( \pm 2.8 \%)$ of the medial prefrontal cortex was damaged across animals, ranging from $55-82 \%$ in total. In all animals the lesion extended dorsally into the anterior cingulate cortex, resulting in minor cell loss, and in four animals there was minor cell loss in the medial orbital cortex. All animals had minor additional damage to secondary motor area and three animals had minor damage in the lateral septum.

In all cases there was extensive damage to the dorsal hippocampus. In five animals damage to the dorsal hippocampus was almost complete, with only three animals having minor sparing in the dentate gyrus; the other five animals had major damage to the dorsal hippocampus with sparing of the medial region of the CA1 and the dentate gyrus. Damage to the ventral hippocampus was less extensive with eight animals having only minor damage to the ventral hippocampus, in the other two animals there was major damage to the ventral hippocampus with sparing occurring in the ventral tip and posterior portion of CA3. In some animals the lesion extended into the subiculum, in three animals there was minor damage to the dorsal subiculum, and in two animals there was minor damage to the ventral subiculum. An average of $54 \%( \pm 4.3 \%)$ of the hippocampus was damaged across animals, ranging from $35-68 \%$ in total. In addition, all animals suffered damage to cortical regions overlying the hippocampus in primary somatosensory and visual cortex, all animals also had a measure of damage to the posterior parietal cortex. The cases with the largest and smallest lesions are shown in Figure $4 B$.

\section{Behavior: novel object preference test}

Object recognition during the test phase

Bilateral lesion. Object recognition performance was assessed in animals with bilateral lesions in the HPC, PRH, and mPFC. As can be seen in Figure 5, $A$ and $B$, the PRH but not the HPC or $\mathrm{mPFC}$ animals were significantly impaired at $5 \mathrm{~min}$ and $3 \mathrm{~h}$ delays. The animals were also tested following a $24 \mathrm{~h}$ delay, and the $\mathrm{PRH}$ but not the HPC animals were significantly impaired (mean 


\section{A mPFC+HPC Contra B mPFC+HPC Ipsi}
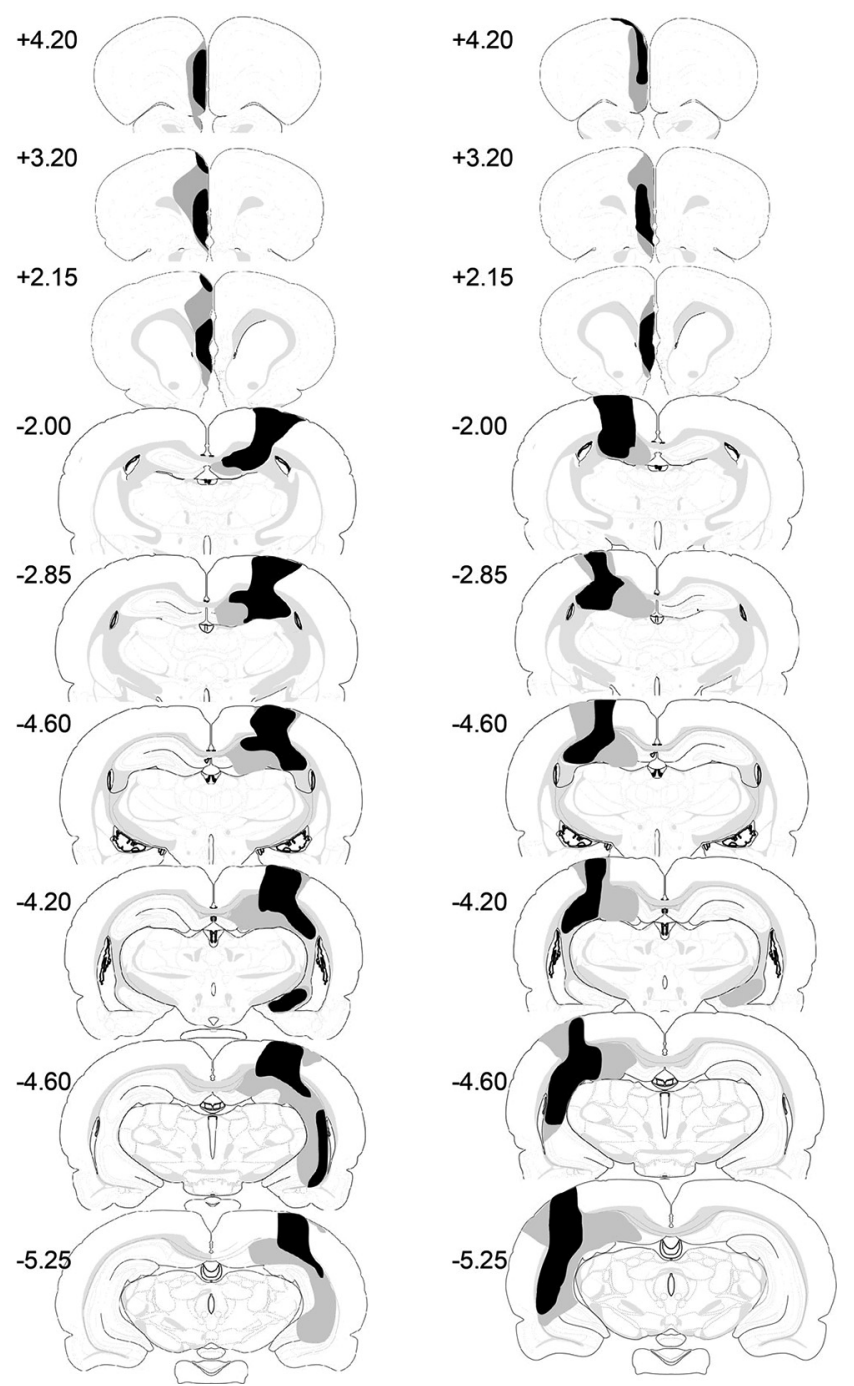

Figure 4. Diagrammatic reconstructions showing the cases with the largest (gray) and smallest (black) lesions in the mPFC + HPC Contra group ( $\boldsymbol{A}$ ) and mPFC + HPC Ipsi group ( $\boldsymbol{B})$. The numbers correspond to the approximate position from bregma (Swanson (1998)).

$\mathrm{DR} \pm$ SEM: SHAM, $0.34 \pm 0.05 ; \mathrm{PRH}, 0.01 \pm 0.08$; HPC, $0.21 \pm$ $0.05)$. At $24 \mathrm{~h}$, the discrimination ratio of the mPFC was lower than at $5 \mathrm{~min}$ and $3 \mathrm{~h}$ delays $(0.14 \pm 0.09)$. Two-way ANOVA with lesion group and delay $(5 \mathrm{~min}, 3 \mathrm{~h}, 24 \mathrm{~h}$ ) as factors revealed a significant main effect of lesion $\left(F_{(3,120)}=27.00, p<0.001\right)$ and of delay $\left(F_{(2,120)}=6.21, p<0.01\right)$, but no lesion-by-delay interaction $\left(F_{(6,120)}=1.89, p>0.05\right)$. Post hoc analyses confirmed that the performance of the $\mathrm{PRH}$ group was significantly worse than the SHAM group $(p<0.001)$ and the HPC and mPFC lesion groups (both $p<0.001$ ); there were no significant differences between any of the other groups. Post hoc analysis of discrimination across the different delays revealed that performance was significantly worse at the $24 \mathrm{~h}$ than the $5 \mathrm{~min}(p<0.01)$ or $3 \mathrm{~h}$ $(p<0.05)$ delay. Additional analysis confirmed that the PRH group failed to show significant discrimination between the novel and familiar objects at the 5 min delay $\left(t_{(9)}=-0.58, p>0.1\right), 3 \mathrm{~h}$ delay $\left(t_{(9)}=-1.066, p>0.1\right)$, or 24 h delay $\left(t_{(9)}=0.15, p>0.1\right)$ and the mPFC group failed to show significant discrimination at the 24 h delay $\left(t_{(11)}=1.76, p>0.1\right)$, although their performance was not significantly worse than the SHAM group. All other
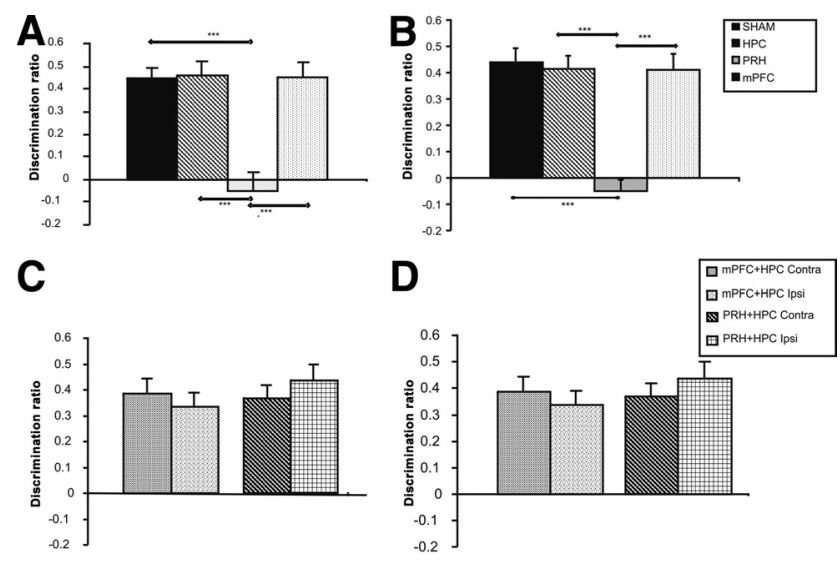

Figure 5. Performance of the experimental groups in the novel object preference task. $\boldsymbol{A}, \boldsymbol{B}$, Performance of the bilateral hippocampal (HPC), perirhinal (PRH), or medial prefrontal cortex (mPFC) lesion groups following a $5 \mathrm{~min}(\boldsymbol{A})$ or a $3 \mathrm{~h}(\boldsymbol{B})$ delay between the sample and test phases. $\boldsymbol{C}, \boldsymbol{D}$, Performance of the medial prefrontal cortex-hippocampal ipsilateral (mPFC + HPC Ipsi) or contralateral (mPFC + HPC Contra) lesions, perirhinal-hippocampal ipsilateral $(\mathrm{PRH}+\mathrm{HPC}$ Ipsi) or contralateral (PRH + HPC Contra) lesion groups, following a $5 \mathrm{~min}(\boldsymbol{C})$ or a $3 \mathrm{~h}(\boldsymbol{D})$ delay. Illustrated for each group is the mean (+SEM) discrimination ratio. ${ }^{* * *} p<$ 0.001 .

groups showed significant discrimination at all delays: SHAM ( 5 min: $t_{(11)}=8.42, p<0.001 ; 3 \mathrm{~h}: t_{(11)}=8.00, p<0.001 ; 24 \mathrm{~h}: t_{(11)}=$ 6.71, $p<0.001)$, HPC (5 min: $t_{(9)}=7.18, p<0.001 ; 3 \mathrm{h:} t_{(9)}=$ 8.02, $p<0.001 ; 24$ h: $\left.t_{(9)}=3.54, p<0.01\right)$, and $\mathrm{mPFC}(5 \mathrm{~min}:$ $\left.t_{(11)}=7.65, p<0.001 ; 3 \mathrm{~h}: t_{(11)}=7.14, p<0.001\right)$. Thus, damage in the hippocampus clearly did not impair the animals' ability to discriminate between a novel and familiar object.

Combined unilateral lesions. Object recognition performance was assessed in animals with combined unilateral lesions in the perirhinal cortex and hippocampus ( $\mathrm{PRH}+\mathrm{HPC})$ or medial prefrontal cortex and hippocampus ( $\mathrm{MPFC}+\mathrm{HPC}$ ) in either the same (Ipsi) or opposite hemispheres (Contra). As can be seen in Figure 5, $C$ and $D$, no lesion group was impaired following the 5 min and $3 \mathrm{~h}$ delays. The animals were also tested following $24 \mathrm{~h}$ delay and again, no lesion group was impaired (mean DR \pm SEM: PRH + HPC Ipsi, $0.35 \pm 0.06 ;$ PRH + HPC Contra, $0.13 \pm 0.05 ;$ $\mathrm{mPFC}+\mathrm{HPC}$ Ipsi, $0.33 \pm 0.05 ; \mathrm{mPFC}+$ HPC Contra, $0.20 \pm$ $0.06)$. There were no significant differences in the discrimination ratios between animals with the combined Ipsi or Contra lesions in the PRH + HPC or mPFC + HPC groups. Two-way ANOVA with lesion group and delay $(5 \mathrm{~min}, 3 \mathrm{~h}, 24 \mathrm{~h}$ ) revealed no significant main effect of lesion $\left(F_{(3,105)}=2.66, p>0.05\right)$ or significant interaction between delay and lesion $\left(F_{(6,105)}=1.10, p>0.1\right)$, although there was a significant effect of delay $\left(F_{(2,105)}=7.31\right.$, $p<0.01)$. Post hoc analysis revealed that discrimination at the $24 \mathrm{~h}$ delay was significantly lower than discrimination at the 5 $\min (p<0.01)$ or $3 \mathrm{~h}(p<0.05)$ delays. Additional analyses showed that at all delays, all groups showed significant discrimination between the novel and familiar objects (PRH + HPC Ipsi: 5 min: $t_{(8)}=6.42, p<0.001 ; 3 \mathrm{~h}: t_{(8)}=7.75, p<0.001 ; 24 \mathrm{~h}$ : $t_{(8)}=6.03, p<0.001 ; \mathrm{PRH}+$ HPC Contra: 5 min: $t_{(9)}=4.65$, $p<0.001 ; 3 \mathrm{~h}: t_{(9)}=7.00, p<0.001 ; 24 \mathrm{~h}: t_{(9)}=2.21, p<0.05$; mPFC + HPC Ipsi: 5 min: $t_{(9)}=4.88, p<0.001 ; 3 \mathrm{~h}: t_{(9)}=$ 5.48, $p<0.001 ; 24 \mathrm{~h}: t_{(9)}=6.20, p<0.001 ; \mathrm{mPFC}+\mathrm{HPC}$ Contra: 5 min: $t_{(9)}=7.16, p<0.001 ; 3 \mathrm{~h}: t_{(9)}=5.92, p<$ $\left.0.001 ; 24 \mathrm{~h}: t_{(9)}=2.87, p<0.05\right)$.

\section{Exploration during sample and test phases}

Table 4 presents the mean exploration values during the sample and test phases for all experimental groups in the $5 \mathrm{~min}$ and 3 and 
Table 4. Exploration values in the sample and test phases for the novel object preference task

\begin{tabular}{|c|c|c|c|c|c|c|}
\hline \multirow[b]{3}{*}{ Lesion } & \multicolumn{6}{|c|}{ Novel object preference } \\
\hline & \multicolumn{2}{|l|}{5 min delay } & \multicolumn{2}{|l|}{$3 \mathrm{~h}$ delay } & \multicolumn{2}{|l|}{$24 \mathrm{~h}$ delay } \\
\hline & $\begin{array}{l}\text { Exploration in } \\
\text { sample phase (s) }\end{array}$ & $\begin{array}{l}\text { Exploration in } \\
\text { test phase (s) }\end{array}$ & $\begin{array}{l}\text { Exploration in } \\
\text { sample phase (s) }\end{array}$ & $\begin{array}{l}\text { Exploration in } \\
\text { test phase (s) }\end{array}$ & $\begin{array}{l}\text { Exploration in } \\
\text { sample phase (s) }\end{array}$ & $\begin{array}{l}\text { Exploration in } \\
\text { test phase (s) }\end{array}$ \\
\hline Sham & $29.2 \pm 2.51$ & $27.1 \pm 2.55$ & $27.2 \pm 2.10$ & $17.3 \pm 2.41$ & $29.8 \pm 1.86$ & $20.3 \pm 2.23$ \\
\hline $\mathrm{HPC}$ & $36.5 \pm 1.97$ & $26.5 \pm 3.70$ & $33.8 \pm 2.11$ & $20.6 \pm 1.49$ & $36.6 \pm 2.17$ & $22.8 \pm 1.58$ \\
\hline mPFC & $34.8 \pm 2.93$ & $24.0 \pm 2.88$ & $31.9 \pm 2.95$ & $20.3 \pm 2.57$ & $33.2 \pm 1.50$ & $17.4 \pm 2.00$ \\
\hline mPFC + HPC Ipsi & $35.5 \pm 2.22$ & $36.9 \pm 4.42$ & $35.4 \pm 1.81$ & $21.5 \pm 2.21$ & $34.9 \pm 1.76$ & $26.3 \pm 2.16$ \\
\hline PRH + HPC Contra & $37.2 \pm 1.80$ & $35.2 \pm 4.14$ & $33.0 \pm 1.96$ & $22.3 \pm 1.59$ & $37.4 \pm 0.74$ & $19.9 \pm 1.75$ \\
\hline PRH + HPC Ipsi & $38.3 \pm 3.78$ & $37.2 \pm 5.41$ & $33.8 \pm 3.57$ & $25.9 \pm 3.12$ & $34.9 \pm 4.00$ & $24.5 \pm 4.24$ \\
\hline
\end{tabular}

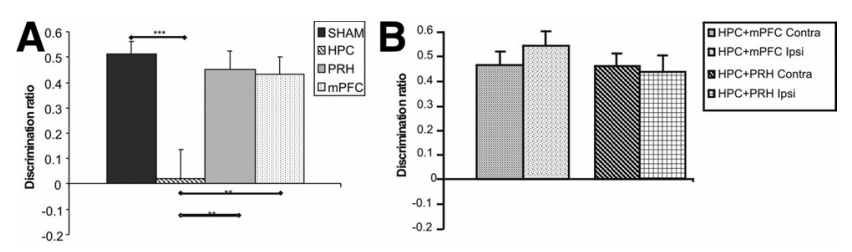

Figure 6. Performance of the experimental groups in the object location task. A, Performance of the sham lesioned animals (SHAM), bilateral hippocampal (HPC), perirhinal (PRH), or medial prefrontal cortex (mPFC) lesion groups. $\boldsymbol{B}$, Performance of animals with combined lesions in the hippocampus and medial prefrontal cortex in the same hemisphere (mPFC + HPC Ipsi) or opposite hemispheres (mPFC + HPC Contra) and animals with combined lesions in the hippocampus and perirhinal cortex in the same hemisphere (PRH + HPC Ipsi) or opposite hemispheres (PRH + HPC Contra) groups. Illustrated for each group is the mean (+SEM) discrimination ratio. ${ }^{* *} p<0.01,{ }^{* * *} p<0.001$.

$24 \mathrm{~h}$ delay experiments. Analysis of the data from the bilateral lesioned animals revealed no significant differences in the total amount of exploration completed in the sample phase at the 5 min or 3 h delay $\left(5 \mathrm{~min}: F_{(3,40)}=2.65, p=0.062 ; 3 \mathrm{~h}: F_{(3,40)}=\right.$ 2.61, $p=0.065)$, although there was a significant difference at $24 \mathrm{~h}\left(F_{(3,40)}=2.97, p<0.05\right)$; post hoc analysis failed to reveal any significant differences between the lesion groups. Analysis of the amount of exploration completed in the test phase revealed no significant differences at any of the delays tested ( $5 \mathrm{~min}: F_{(3,40)}=0.22$, $\left.p>0.1 ; 3 \mathrm{~h}: F_{(3,40)}=0.45, p>0.1 ; 24 \mathrm{~h}: F_{(3,40)}=1.20, p>0.1\right)$.

Analysis of the data from the disconnection lesion groups revealed no significant differences in the total amount of exploration completed in the sample phase $\left(5 \mathrm{~min}: F_{(3,35)}=0.47, p>\right.$ $\left.0.1 ; 3 \mathrm{~h}: F_{(3,35)}=3.11, p>0.05 ; 24 \mathrm{~h}: F_{(3,35)}=0.80, p>0.1\right)$ or in the amount of exploration completed in the test phase at the 5 min or 3 h delay $\left(5 \mathrm{~min}: F_{(3,35)}=0.04, p>0.1 ; 3 \mathrm{h:} F_{(3,35)}=1.60\right.$, $p>0.1)$, although there was a significant effect of lesion at the 24 h delay $\left(F_{(3,35)}=5.82, p<0.01\right)$. However, post hoc analysis revealed that this significant main effect reflected a significantly lower amount of exploration completed by the PRH + HPC Ipsi $(p<0.05)$ and PRH-HPC Contra $(p<0.01)$ groups compared with the $\mathrm{mPFC}+\mathrm{HPC}$ Contra group. Importantly, there were no significant differences between the Ipsi and Contra groups within the mPFC-HPC or PRH-HPC lesions.

\section{Object location}

Recognition during test phase. As shown in Figure 6A, the HPC lesion animals were significantly impaired on the object location task following a 5 min delay. The animals were also tested following a $24 \mathrm{~h}$ delay, and the HPC lesion group again were the only group to be impaired in this task (mean DR \pm SEM: SHAM, $0.39 \pm 0.05 ; \mathrm{HPC},-0.06 \pm 0.07$; PRH, $0.33 \pm 0.06$; mPFC, $0.29 \pm 0.06)$. ANOVA revealed a significant main effect of lesion group $\left(F_{(3,80)}=17.15, p<0.001\right)$ and delay $\left(F_{(1,80)}=5.41, p<\right.$ $0.05)$, but no significant interaction between lesion and delay $\left(F_{(3,80)}=0.06, p>0.1\right)$. Post hoc analyses showed that the performance of the HPC group was significantly worse than the SHAM $(p<0.001)$, PRH $(p<0.01)$, and mPFC $(p<0.01)$ groups. Additional analyses revealed that the HPC group failed to discriminate between the moved and unmoved object $\left(5 \mathrm{~min}: t_{(9)}=\right.$ $\left.0.17, p>0.1 ; 24 \mathrm{~h}: t_{(9)}=0.90, p>0.1\right)$ at both $5 \mathrm{~min}$ and $24 \mathrm{~h}$ delay, whereas the SHAM ( 5 min: $t_{(11)}=9.95, p<0.001 ; 24 \mathrm{~h}: t_{(11)}=7.35$, $p<0.001$ ), $\mathrm{PRH}$ (5 min: $t_{(9)}=6.08, p<0.001 ; 24 \mathrm{~h}: t_{(9)}=5.04, p<$ 0.001 ), and $\mathrm{mPFC}\left(5 \mathrm{~min}: t_{(11)}=6.26, p<0.001 ; 24 \mathrm{~h}: t_{(11)}=5.00\right.$, $p<0.001)$ groups showed significant discrimination regardless of the delay used.

As shown in Figure $6 B$, none of the unilateral lesion groups were impaired following a 5 min delay. The animals were also tested following a $24 \mathrm{~h}$ delay and were also unimpaired (mean $\mathrm{DR} \pm$ SEM: PRH + HPC Ipsi, $0.48 \pm 0.08 ; \mathrm{PRH}+$ HPC Contra, $0.50 \pm 0.04 ; \mathrm{mPFC}+\mathrm{HPC}$ Ipsi, $0.40 \pm 0.07 ; \mathrm{mPFC}+\mathrm{HPC}$ Contra, $0.48 \pm 0.07)$. ANOVA found no significant main effect of lesion group $\left(F_{(3,70)}=0.04, p>0.1\right)$ or delay $\left(F_{(1,70)}=0.07, p>\right.$ $0.1)$ and no significant interaction between lesion group and delay $\left(F_{(3,70)}=1.13, p>0.1\right)$. Further analyses showed that the mPFC + HPC Contra (5 min: $t_{(9)}=8.02, p<0.001 ; 24 \mathrm{~h}: t_{(9)}=$ $6.64, p<0.001), \mathrm{mPFC}+$ HPC Ipsi $\left(5 \mathrm{~min}: t_{(9)}=8.81, p<0.001\right.$; $\left.24 \mathrm{~h}: t_{(9)}=5.38, p<0.001\right), \mathrm{PRH}+\mathrm{HPC}$ Contra $\left(5 \mathrm{~min}: t_{(9)}=\right.$ 8.49, $\left.p<0.001 ; 24 \mathrm{~h} t_{(9)}=11.87, p<0.001\right)$, and PRH + HPC Ipsi ( 5 min: $t_{(8)}=7.572, p<0.001 ; 24$ h: $t_{(8)}=6.71, p<0.001$ ) groups showed significant discrimination between the moved and unmoved object at both delays tested.

Exploration during the sample and test phases. Table 5 presents the mean exploration values during the sample and test phases for all experimental groups. In the sample phase, the HPC group completed significantly more exploration in the sample phase compared with the other groups (SHAM, PRH, mPFC) ( 5 min: $F_{(3,40)}=3.97, p<0.05 ; 24$ h: $\left.F_{(3,40)}=3.72, p<0.05\right)$. Post hoc analyses confirmed that the HPC group completed significantly more exploration than the SHAM group before both delays (5 $\min$ and $24 \mathrm{~h} ; p<0.05$ ). Analysis of the amount of exploration completed in the test phase revealed no significant main effect of lesion at the 5 min delay $\left(F_{(3,40)}=0.80, p>0.1\right)$; however, there was a significant main effect of lesion at the $24 \mathrm{~h}$ delay $\left(F_{(3,40)}=\right.$ 4.08, $p<0.05$ ). Post hoc analysis revealed that the HPC group completed significantly more exploration than the SHAM group $(p<0.05)$.

Analysis of the amount of exploration completed in the sample phase revealed no significant main effect of lesion in animals with the unilateral combined lesions (5 min: $F_{(3,35)}=2.20, p>$ $\left.0.1 ; 24 \mathrm{~h}: F_{(3,35)}=0.52, p>0.1\right)$. Analysis of the amount of 
Table 5. Mean exploration values in the sample and test phases for the object location ( $5 \mathrm{~min}$ and $24 \mathrm{~h}$ delay) and object-in-place memory tasks

\begin{tabular}{|c|c|c|c|c|c|c|}
\hline \multirow[b]{3}{*}{ Lesion } & \multicolumn{4}{|l|}{ Object location } & & \\
\hline & \multicolumn{2}{|l|}{5 min delay } & \multicolumn{2}{|l|}{$24 \mathrm{~h}$ delay } & \multicolumn{2}{|l|}{ Object in place } \\
\hline & $\begin{array}{l}\text { Exploration in } \\
\text { sample phase (s) }\end{array}$ & $\begin{array}{l}\text { Exploration in } \\
\text { test phase (s) }\end{array}$ & $\begin{array}{l}\text { Exploration in } \\
\text { sample phase (s) }\end{array}$ & $\begin{array}{l}\text { Exploration in } \\
\text { test phase (s) }\end{array}$ & $\begin{array}{l}\text { Exploration in } \\
\text { sample phase (s) }\end{array}$ & $\begin{array}{l}\text { Exploration in } \\
\text { test phase (s) }\end{array}$ \\
\hline Sham & $28.6 \pm 1.54$ & $17.3 \pm 1.23$ & $31.6 \pm 2.41$ & $13.0 \pm 0.53$ & $42.6 \pm 3.21$ & $19.8 \pm 2.61$ \\
\hline HPC & $40.6 \pm 3.58$ & $21.5 \pm 3.28$ & $47.4 \pm 3.47$ & $19.4 \pm 1.68$ & $61.3 \pm 5.27$ & $31.1 \pm 3.08$ \\
\hline $\mathrm{mPFC}$ & $37.1 \pm 3.88$ & $17.6 \pm 2.44$ & $34.0 \pm 3.72$ & $15.2 \pm 1.24$ & $59.6 \pm 5.68$ & $22.2 \pm 2.57$ \\
\hline PRH & $30.7 \pm 2.32$ & $16.7 \pm 2.14$ & $37.3 \pm 4.44$ & $18.0 \pm 2.12$ & $46.7 \pm 4.45$ & $20.0 \pm 1.45$ \\
\hline $\mathrm{mPFC}+\mathrm{HPC}$ Contra & $56.3 \pm 6.29$ & $27.2 \pm 3.21$ & $45.4 \pm 5.44$ & $23.7 \pm 3.19$ & $76.4 \pm 5.58$ & $33.4 \pm 4.70$ \\
\hline mPFC + HPC Ipsi & $40.4 \pm 4.54$ & $23.1 \pm 2.60$ & $46.9 \pm 4.70$ & $18.5 \pm 1.69$ & $59.5 \pm 4.85$ & $27.5 \pm 3.14$ \\
\hline PRH + HPC Contra & $40.9 \pm 4.38$ & $22.5 \pm 3.11$ & $39.3 \pm 2.21$ & $19.9 \pm 1.91$ & $66.0 \pm 4.34$ & $27.3 \pm 1.34$ \\
\hline PRH + HPC Ipsi & $45.7 \pm 5.01$ & $23.8 \pm 3.34$ & $43.7 \pm 5.91$ & $21.1 \pm 2.20$ & $61.7 \pm 7.27$ & $23.7 \pm 2.48$ \\
\hline
\end{tabular}
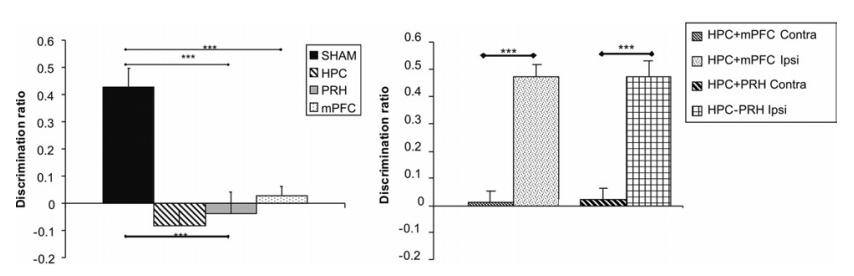

Figure 7. Performance of the experimental groups in the object-in-place task. Left, Performance of the sham lesioned animals (SHAM), bilateral hippocampal (HPC), perirhinal (PRH), or medial prefrontal cortex (mPFC) lesion groups. Right, Performance of animals with combined lesions in the hippocampus and medial prefrontal cortex in the same hemisphere (mPFC + HPC Ipsi) or opposite hemispheres (mPFC + HPC Contra) and animals with combined lesions in the hippocampus and perirhinal cortex in the same hemisphere (HPC + PRH Ipsi) or opposite hemispheres (PRH + HPC Contra) groups. Illustrated for each group is the mean (+SEM) discrimination ratio. ${ }^{* * *} p<0.001$

exploration completed in the test phase also revealed no significant main effect of lesion ( 5 min: $F_{(3,35)}=0.47, p>0.1 ; 24 \mathrm{~h}$ : $\left.F_{(3,35)}=0.97, p>0.1\right)$.

\section{Behavior: object-in-place}

\section{Recognition during test phase}

As shown in Figure 7 (left), animals in the HPC, PRH, and mPFC groups were significantly impaired in the object-in-place task following a 5 min delay. ANOVA with lesion group as a factor revealed a significant main effect of lesion group $\left(F_{(3,40)}=14.27\right.$, $p<0.001)$ and post hoc analysis revealed that the performance of the HPC, PRH, and mPFC groups was significantly worse than the performance of the SHAM group (for all, $p<0.001$ ). There were no significant differences between any of the other groups. Further analyses confirmed that the SHAM group showed significant discrimination between the rearranged and non-rearranged objects $\left(t_{(11)}=5.95, p<0.001\right)$, while the $\operatorname{HPC}\left(t_{(9)}=-1.52, p>\right.$ $0.1), \operatorname{PRH}\left(t_{(9)}=-0.457, p>0.1\right)$, and $\operatorname{mPFC}\left(t_{(11)}=0.75, p>\right.$ $0.1)$ groups all failed to discriminate.

Figure 7 (right) shows that both the PRH + HPC Contra and $\mathrm{mPFC}+\mathrm{HPC}$ Contra groups were significantly impaired in the object-in-place task. ANOVA with lesion group as a factor revealed a significant main effect of lesion group $\left(F_{(3,35)}=35.17\right.$, $p<0.001)$. Post hoc analysis revealed that the performance of the mPFC + HPC Contra group was significantly worse than the performance of the mPFC + HPC Ipsi group $(p<0.001)$ and that the performance of the PRH + HPC Contra group was significantly worse than the PRH + HPC Ipsi group $(p<0.001)$. Additional analysis revealed that the $\mathrm{mPFC}+\mathrm{HPC}$ Ipsi $\left(t_{(9)}=\right.$ 9.57, $p<0.001)$ and PRH + HPC Ipsi $\left(t_{(8)}=11.07, p<0.001\right)$ groups showed significant discrimination between the rearranged and non-rearranged objects; the mPFC + HPC Contra

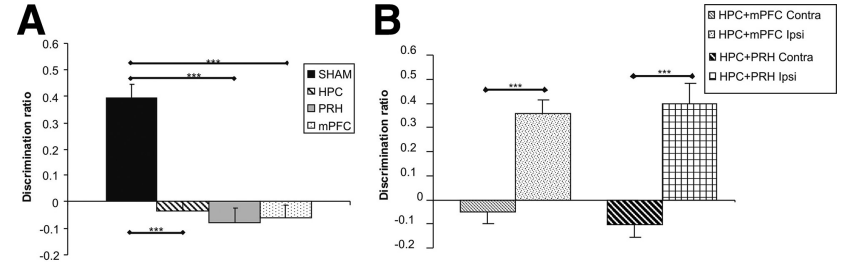

Figure 8. Performance of the experimental groups in the temporal order memory task. $\boldsymbol{A}$, Performance of the sham lesioned animals (SHAM), bilateral hippocampal (HPC), perirhinal (PRH), and medial prefrontal cortex (mPFC) lesion groups. $\boldsymbol{B}$, Performance of animals with combined lesions in the hippocampus and medial prefrontal cortex in the same hemisphere (mPFC + HPC Ipsi) or opposite hemispheres (mPFC + HPC Contra) and animals with combined lesions in the hippocampus and perirhinal cortex in the same hemisphere (PRH $+\mathrm{HPC}$ Ipsi) or opposite hemispheres (PRH + HPC Contra) groups. Illustrated for each group is the mean $\left(+\right.$ SEM) discrimination ratio. ${ }^{* * *} p<0.001$.

$\left(t_{(9)}=0.33, p>0.1\right)$ and PRH $+\mathrm{HPC}$ Contra $\left(t_{(9)}=0.61, p>\right.$ $0.1)$ groups failed to discriminate.

Exploration in sample and test phases

Table 5 shows the mean levels of exploration completed in either the sample phase or test phase for all lesion groups. ANOVA with lesion group (SHAM, HPC, PRH mPFC) as a factor revealed a significant main effect of lesion group for both the amount of exploration completed in the sample phase $\left(F_{(3,40)}=4.56, p<\right.$ $0.01)$ and the amount of exploration completed in the test phase $\left(F_{(3,40)}=4.24, p<0.05\right)$. Post hoc analysis revealed that the HPC group completed significantly more exploration than the SHAM group in both the sample and test phases (both, $p<0.05$ ). In addition, the mPFC group completed significantly more exploration than the SHAM group in the sample phase $(p<0.05)$ and the HPC group completed significantly more exploration than the PRH group in the test phase $(p<0.05)$.

Analysis of the levels of exploration in the animals with the unilateral combined lesions found no significant main effect of lesion (sample phase: $F_{(3,35)}=2.13, p>0.1$; test phase: $F_{(3,35)}=$ $1.57, p>0.1)$.

\section{Behavior: temporal order memory}

Recognition during test phase

Figure $8 A$ shows that the performances of the HPC, PRH, and $\mathrm{mPFC}$ bilateral lesion groups were impaired in the temporal order memory task. ANOVA with lesion group as a factor revealed a significant main effect of lesion group $\left(F_{(3,40)}=19.04, p<\right.$ 0.001 ) and post hoc analyses confirmed that the performance of the HPC, PRH, and mPFC groups was significantly worse compared with the SHAM group (for all comparisons, $p<0.001$ ). The SHAM group showed significant discrimination between the 
Table 6. Mean exploration values in the sample and test phases for the temporal order memory task

\begin{tabular}{llll}
\hline \multicolumn{3}{l}{ Temporal order memory } & \\
\cline { 2 - 4 } Lesion & $\begin{array}{l}\text { Exploration in } \\
\text { sample phase 1 }(\mathrm{s})\end{array}$ & $\begin{array}{l}\text { Exploration in } \\
\text { sample phase 2 (s) }\end{array}$ & $\begin{array}{l}\text { Exploration in } \\
\text { test phase (s) }\end{array}$ \\
\hline Sham & $27.7 \pm 1.46$ & $30.8 \pm 1.93$ & $19.1 \pm 2.51$ \\
HPC & $45.1 \pm 4.88$ & $42.0 \pm 4.57$ & $19.7 \pm 1.86$ \\
mPFC & $39.8 \pm 3.93$ & $37.7 \pm 4.29$ & $19.4 \pm 2.01$ \\
PRH & $32.6 \pm 2.43$ & $31.4 \pm 2.16$ & $18.6 \pm 1.80$ \\
mPFC + HPC Contra & $56.2 \pm 7.80$ & $62.7 \pm 6.65$ & $33.3 \pm 3.27$ \\
mPFC + HPC Ipsi & $41.3 \pm 3.53$ & $45.1 \pm 4.75$ & $22.8 \pm 3.26$ \\
PRH + HPC Contra & $45.4 \pm 3.96$ & $43.6 \pm 4.25$ & $25.2 \pm 2.06$ \\
PRH + HPC Ipsi & $50.1 \pm 6.34$ & $49.9 \pm 5.74$ & $22.2 \pm 3.68$ \\
\hline
\end{tabular}

object presented least recently and the object presented most recently $\left(t_{(11)}=7.27, p<0.001\right)$, while the $\operatorname{HPC}\left(t_{(9)}=-0.87\right.$, $p>0.1), \operatorname{PRH}\left(t_{(9)}=-1.17, p>0.1\right)$, and $\operatorname{mPFC}\left(t_{(11)}=-1.23\right.$, $p>0.1)$ groups failed to show significant discrimination.

Figure $8 B$ shows that the PRH + HPC Contra and mPFC + HPC Contra groups were impaired in the temporal order memory task. ANOVA with lesion group as a factor revealed a significant main effect of lesion group $\left(F_{(3,35)}=18.15, p<0.001\right)$. Post hoc analysis revealed that the performance of the PRH + HPC Contra group was significantly worse than the performance of the $\mathrm{PRH}+$ HPC Ipsi group $(p<0.001)$ and that the performance of the mPFC + HPC Contra group was significantly worse than the $\mathrm{mPFC}+\mathrm{HPC}$ Ipsi group $(p<0.001)$. Additional analysis confirmed that the mPFC + HPC Ipsi $\left(t_{(9)}=6.43, p<0.001\right)$ and the $\mathrm{PRH}+\mathrm{HPC}$ Ipsi $\left(t_{(8)}=4.62, p<0.01\right)$ groups showed significant discrimination between the object presented least recently and the object presented most recently; in contrast, the mPFC + HPC Con$\operatorname{tra}\left(t_{(9)}=-0.93, p>0.1\right)$ and the PRH + HPC Contra $\left(t_{(9)}=\right.$ $-2.05, p>0.05)$ groups failed to show significant discrimination.

\section{Exploration during sample and test phases}

Table 6 shows the mean levels of exploration during sample phase 1 , sample phase 2 , and the test phase. ANOVA with lesion group (SHAM, HPC, PRH, mPFC) and sample phase (1 or 2) as factors revealed no significant interaction between sample phase and lesion $\left(F_{(3,40)}=0.85, p>0.1\right)$ and no significant main effect of sample phase $\left(F_{(1,40)}=0.31, p>0.1\right)$. The analysis did reveal a significant main effect of lesion $\left(F_{(3,40)}=5.11, p<0.01\right)$ and post hoc analysis revealed that the HPC group completed significantly more exploration in both the sample phases compared with the SHAM group $(p<0.01)$. Analysis of the amount of exploration completed in the test phase did not reveal any significant differences $\left(F_{(3,40)}=0.05, p>0.1\right)$.

ANOVA with lesion group (PRH + HPC Ipsi, PRH + HPC Contra, mPFC + HPC Ipsi, mPFC + HPC Contra) and sample phase as factors revealed no significant differences (lesion $X$ sample interaction: $F_{(3,35)}=0.57, p>0.1$; main effect of sample: $F_{(1,35)}=0.67, p>0.1$; main effect of lesion: $F_{(3,35)}=2.42, p>$ $0.05)$. Analysis of the amount of exploration completed in the test phase did not reveal any significant differences $\left(F_{(3,35)}=2.65\right.$, $p>0.05)$.

\section{Discussion}

The present study had two aims: the first was to assess whether the role of the hippocampus in recognition memory is dependent on the type of stimulus material to be remembered and the second was to examine the extent to which the hippocampus interacts with the perirhinal and medial prefrontal cortices to enable recognition memory judgments for different types of information.
Bilateral ablation of the hippocampus significantly impaired object location memory, object-in-place associative memory, and temporal order memory. In contrast, there was no effect of hippocampal lesions on performance of the object recognition task following a $5 \mathrm{~min}, 3 \mathrm{~h}$, or $24 \mathrm{~h}$ delay. In the second series of experiments, disconnection of the hippocampus from either the perirhinal or medial prefrontal cortex produced significant impairments in the object-in-place associative memory and in the temporal order memory tasks, but had no effect on the object location or object recognition tasks. These data demonstrate for the first time that hippocampus is a crucial component of a neural system, which, together with the perirhinal and medial prefrontal cortices, functions to support object-in-place memory and temporal order/recency memory.

In this study, bilateral hippocampal lesions had no effect on standard object recognition memory but significantly impaired memory for an object's location, while lesions in the perirhinal cortex produced the opposite pattern of effects. This double dissociation between the effects of hippocampal and perirhinal damage on object and spatial memory has been reported previously (Winters et al., 2004), but the present study had the advantage of using identical apparatus retention delays and stimulus types in both the spatial and object recognition memory tasks. Thus, the distinct effects of the hippocampal and perirhinal lesions cannot be explained by differences in the attentional or response requirements of the procedures. Further hippocampal lesions produced significant impairments in the object-in-place and temporal order tasks while having no effect on object recognition, hence the detrimental effect of the hippocampal lesions cannot be explained by an effect on the rats' perceptual abilities or preference for novelty. The animals with bilateral hippocampal lesions did show significantly different levels of exploration in the sample phases of the temporal order memory task and increased exploration in the sample and test phases of the object location and object-in-place tasks; however, as this group showed higher levels of exploration during encoding and recall, these differences in exploration levels cannot account for the memory impairments observed. In summary, these data show that the role of the hippocampus and perirhinal cortex may be doubly dissociated purely in terms of the type of the information required for the recognition memory judgment, that is, judgment of prior occurrence for individual items but not spatial location relies on the perirhinal cortex, while recognition memory involving spatial information depends on the hippocampus and not the perirhinal cortex. Recognition memory that involves multiple items and their spatial/contextual associations or the relative recency in which items are encountered depends on the perirhinal cortex, hippocampus, and medial prefrontal cortex.

Some papers have reported that manipulations of the hippocampus impair novel object preference tasks (Mansuy et al., 1998; Pittenger et al., 2002; Oh et al., 2010). However, in a number of these studies such variation may be accounted for by differences in the experimental paradigms used, in particular the type or number of stimuli presented in the sample phase. In these experiments, the sample phase involves the presentation of two different objects (e.g., objects A and B) and, following the retention delay, one of the objects (e.g., object B) is replaced with the novel object $C$. In contrast, in the present study we presented two identical objects in the sample phase and replaced one of these objects with an object never previously encountered by the subject. Thus, in those studies that show an involvement of the hippocampus in object recognition, the presence of two different objects in the sample phase might create additional contextual 
cues or object-object associations that are themselves vulnerable to hippocampal damage. Indeed, previous studies have suggested that the hippocampus can play a role in object recognition if such cues are present (Rudy, 2009; Oliveira et al., 2010).

The demonstration that disconnection of the hippocampus from either the perirhinal or medial prefrontal cortex produces significant impairments in the object-in-place task is an important addition to our knowledge of which regions interact during recognition memory tasks involving the integration of object and spatial information. From the results of our previous disconnection studies, we hypothesized that the perirhinal cortex was critical for processing object information, while the mPFC was important for the formation of associations between the object and place information (Barker et al., 2007). As the present results show that hippocampus, but not the perirhinal or medial prefrontal cortex, is critical for object location memory, its principal role within the circuit may be in processing the place memory information. In support of this hypothesis, previous studies have suggested that plasticity at hippocampal-prefrontal synapses modulates the transfer of spatial information from the hippocampus to the prefrontal cortex, a process that would be clearly critical for object-in-place memory (Seamans et al., 1998; Gurden et al., 2000). Another possibility is that the object-place information is integrated within the hippocampus. Electrophysiological recording studies show that the incidence of neuronal response changes related to the familiarity of individual stimuli is low in the hippocampus (Xiang and Brown, 1998); however, hippocampal neurons do respond to spatial location information and on some occasions show a selective response to the position of a stimulus in space (Rolls et al., 1989). Finally, we cannot exclude the possibility that performance of the object-in-place task is a property of the hippocampal-prefrontal-perirhinal circuit as a whole. Further experiments to explore these possibilities are clearly required.

Our present data demonstrate that the hippocampus, perirhinal cortex, and medial prefrontal cortex are crucial for remembering sequential order, independent of either familiarity or spatial information, and that these regions form a function network. Thus, one view may be that the role of the hippocampus is to process the object information (from the perirhinal cortex) and the interaction between the hippocampus and medial prefrontal cortex is necessary for higher-order cognitive functions such as ordering of the objects or planning of appropriate response strategies.

An alternative view, however, suggests that each neural region does not engage in separate cognitive functions, but rather that the perirhinal cortex and hippocampus lie within a representational hierarchy in which the hippocampus is able to represent the conjunction of an object with time and space (Cowell et al., 2006, 2010). Interestingly, the effects of manipulations of the perirhinal-hippocampal-medial prefrontal network on the object-in-place and temporal order memory tasks are identical, so clearly one cannot rule out the possibility that these tasks rely on the same computational processes with different types of information.

Disconnection of any pair of structures in the hippocampal, perirhinal, or medial prefrontal system produces object-in-place or temporal order/recency recognition memory impairments, indicating that interactions involving all, and not merely a pair of, these structures are necessary. Thus, for example, the presence of location information in the hippocampus and object information in perirhinal cortex is insufficient in itself to allow the task to be performed. Furthermore, interactions involving the hip- pocampus and perirhinal cortex are not sufficient to give unimpaired performance of the object-in-place task if interactions with medial prefrontal cortex are prevented. Accordingly, successful performance of the task is a property of the perirhinalhippocampal-medial prefrontal network: neither any one nor any pair of the component structures is sufficient. In turn, this network interdependency raises the possibility that the information necessary to solve the task may be held in the interactions between the neurons of the component structures rather than in a group of neurons residing in one of the structures. Importantly, this conclusion implies that the functions of an individual brain region cannot always be determined by considering it in isolation from its interactions with other parts of networks to which it belongs.

In conclusion, the present studies demonstrate that one aspect of recognition memory, that is, judgment of prior occurrence for individual items, relies on the perirhinal cortex, while recognition memory that involves multiple items and their contextual associations or the temporal order in which items are encountered depends on interactions between the perirhinal cortex, hippocampus, and medial prefrontal cortex. Thus, the hippocampus plays a role in recognition memory when such memory involves information that has a spatial component, i.e., remembering that a particular stimulus occurred in a particular place (Parkinson et al., 1988; Gaffan, 1994; Eichenbaum, 2000), or when the memory contains a temporal/recency component.

\section{References}

Barker GR, Bird F, Alexander V, Warburton EC (2007) Recognition memory for objects, place and temporal order: a disconnection analysis of the role of the medial prefrontal cortex and perirhinal cortex. J Neurosci 27:2948-2957.

Block AE, Dhanji H, Thompson-Tardif SF, Floresco SB (2007) Thalamicprefrontal cortical-ventral striatal circuitry mediates dissociable components of strategy set shifting. Cereb Cortex 17:1625-1636.

Burwell RD, Witter MP, Amaral DG (1995) The perirhinal and postrhinal cortices of the rat: a review of the neuroanatomical literature and comparison with findings from the monkey brain. Hippocampus 5:390-408.

Bussey TJ, Muir JL, Aggleton JP (1999) Functionally dissociating aspects of event memory: the effects of combined perirhinal and postrhinal cortex lesions on object and place memory in the rat. J Neurosci 19:495-502.

Bussey TJ, Duck J, Muir JL, Aggleton JP (2000) Distinct patterns of behavioural impairments resulting from fornix transection or neurotoxic lesions of the perirhinal and postrhinal cortices in the rat. Behav Brain Res 111:187-202.

Chiba AA, Kesner RP, Reynolds AM (1994) Memory for spatial location as a function of temporal lag in rats: role of hippocampus and medial prefrontal cortex. Behav Neural Biol 61:123-131.

Clark RE, Zola SM, Squire LR (2000) Impaired recognition memory in rats after damage to the hippocampus. J Neurosci 20:8853-8860.

Clark RE, West AN, Zola SM, Squire LR (2001) Rats with lesions of the hippocampus are impaired on the delayed nonmatching-to-sample task. Hippocampus 11:176-186.

Cowell RA, Bussey TJ, Saksida LM (2006) Why does brain damage impair memory? A connectionist model of object recognition memory in perirhinal cotex. J Neurosci 26:12186-12197.

Cowell RA, Bussey TJ, Saksida LM (2010) Components of recognition memory: dissociable cognitive processes or just differences in representational complexity? Hippocampus 20:1245-1262.

Dix SL, Aggleton JP (1999) Extending the spontaneous preference test of recognition: evidence of object-location and object-context recognition. Behav Brain Res 99:191-200.

Eichenbaum H (2000) Cortical-hippocampal networks for declarative memory. Nat Rev Neurosci 1:41-50.

Ennaceur A, Delacour J (1988) A new one-trial test for neurobiological studies of memory in rats. 1. Behavioral data. Behav Brain Res 31:47-59.

Ennaceur A, Neave N, Aggleton JP (1996) Neurotoxic lesions of the perirhinal cortex do not mimic the behavioural effects of fornix transection in the rat. Behav Brain Res 80:9-25. 
Fortin NJ, Agster KL, Eichenbaum HB (2002) Critical role of the hippocampus in memory for sequences of events. Nat Neurosci 5:458-462.

Forwood SE, Winters BD, Bussey TJ (2005) Hippocampal lesions that abolish spatial maze performance spare object recognition memory at delays of up to 48 hours. Hippocampus 15:347-355.

Gaffan D (1994) Dissociated effects of perirhinal cortex ablation, fornic transaction and amygdalectomy: evidence of multiple memory systems in the primate temporal lobe. Exp Brain Res 99:411-422.

Glenn MJ, Mumby DG (1998) Place memory is intact in rats with perirhinal cortex lesions. Behav Neurosci 112:1353-1365.

Good MA, Barnes P, Staal V, McGregor A, Honey RC (2007) Context- but not familiarity-dependent forms of object recognition are impaired following excitotoxic hippocampal lesions in rats. Behav Neurosci 121:218-223.

Gurden H, Takita M, Jay TM (2000) Essential role of D1 but not D2 receptors in the NMDA receptor-dependent long-term potentiation at hippocampal-prefrontal cortex synapses in vivo. J Neurosci 20:RC106.

Hannesson DK, Vacca G, Howland JG, Phillips AG (2004) Medial prefrontal cortex is involved in spatial temporal order memory but not spatial recognition memory in tests relying on spontaneous exploration in rats. Behav Brain Res 153:273-285.

Jay TM, Witter MP (1991) Distribution of hippocampal CA1 and subicular efferents in the prefrontal cortex of the rat studied by means of anterograde transport of Phaseolus vulgaris-leucoagglutin. J Comp Neurol 313:574-586.

Kesner RP, Novak JM (1982) Serial position curve in rats: role of the dorsal hippocampus. Science 218:173-175.

Langston RF, Wood ER (2010) Associative recognition and the hippocampus: Differential effects of hippocampal lesions on object-place, objectcontext and object-place-context memory. Hippocampus 20:1139-1153.

Mansuy IM, Mayford M, Jacob B, Kandel ER, Bach ME (1998) Restricted and regulated overexpression reveals calcineurin as a key component in the transition from short-term to long-term memory. Cell 92:39-49.

Mumby DG, Pinel JP (1994) Rhinal cortex lesions and object recognition in rats. Behav Neurosci 108:11-18.

Mumby DG, Gaskin S, Glenn MJ, Schramek TE, Lehmann H (2002) Hippocampal damage and exploratory preferences in rats: memory for objects, places and contexts. Learn Mem 9:49-57.

Norman G, Eacott MJ (2004) Impaired object recognition with increasing levels of feature ambiguity in rats with perirhinal cortex lesions. Behav Brain Res 148:79-91.

Oh D, Han S, Seo J, Lee JR, Choi J, Groffen J, Kim K, Cho YS, Choi HS, Shin H, Woo J, Won H, Park SK, Kim SY, Jo J, Whitcomb DJ, Cho K, Kim H, Bae YC, Heisterkamp N, Choi SY, Kim E (2010) Regulation of synaptic
Racl activity, long-term potentiation maintenance, and learning and memory by BCR and ABR Rac GTPase-activating proteins. J Neurosci 30:14134-14144.

Oliveira AM, Hawk JD, Abel T, Havekes R (2010) Post training reversible inactivation of the hippocampus enhances novel object recognition memory. Learn Mem 17:155-160.

Parkinson JK, Murray EA, Mishkin M (1988) A selective mnemonic role for the hippocampus in monkeys: memory for the location of objects. J Neurosci 8:4159-4167.

Pittenger C, Huang YY, Paletzki RF, Bourtchouladze R, Scanlin H, Vronskaya S, Kandel ER (2002) Reversible inhibition of CREB/ATF transcription factors in region CA1 of the dorsal hippocampus disrupts hippocampusdependent spatial memory. Neuron 34:447-462.

Rolls ET, Miyashita Y, Cahusac PM, Kesner RP, Niki H, Feigenbaum JD, Bach L (1989) Hippocampal neurons in the monkey with activity related to the place in which a stimulus is shown. J Neurosci 9:1835-1845.

Rudy JW (2009) Context representations, context functions, and the parahippocampal-hippocampal system. Learn Mem 16:573-585.

Seamans JK, Floresco SB, Phillips AG (1998) D-1 receptor modulation of hippocampal-prefrontal cortical circuits integrating spatial memory with executive functions in the rat. J Neurosci 18:1613-1621.

Swanson LW (1998) Brain maps: structure of the rat brain. Amsterdam: Elsevier.

Vorobyov NA (1998) A model for hippocampal memory processing of successive representations. In: Downward processes in the perception representation mechanisms: series on biophysics and biocybernetics, vol 6 (Taddei-Ferretti C, Musio C, eds), pp 309-313. Singapore: World Scientific.

Warburton EC, Baird AL, Morgan A, Muir JL, Aggleton JP (2000) Disconnecting hippocampal projections to the anterior thalamus produces deficits on tests of spatial memory in rats. Eur J Neurosci 12:1714-1726.

Warburton EC, Baird A, Morgan A, Muir JL, Aggleton JP (2001) The conjoint importance of the hippocampus and anterior thalamic nuclei for allocentric spatial learning: evidence from a disconnection study in the rat. J Neurosci 21:7323-7330.

Winters BD, Forwood SE, Cowell RA, Saksida LM, Bussey TJ (2004) Double dissociation between the effects of peri-postrhinal cortex and hippocampal lesions on tests of object recognition and spatial memory: heterogenity of function within the temporal lobe. J Neurosci 24:5901-5908.

Xiang JZ, Brown MW (1998) Differential neuronal encoding of novelty, familiarity and recency in regions of the anterior temporal lobe. Neuropharmacology 37:657-676. 